Old Dominion University

ODU Digital Commons

VMASC Publications

Virginia Modeling, Analysis \& Simulation Center

2012

\title{
Distribution Analysis of Freight Transportation with Gravity Model and Genetic Algorithm
}

Jun Duanmu

Old Dominion University

Peter Foytik

Old Dominion University, pfoytik@odu.edu

Asad Khattak

Old Dominion University

R. Michael Robinson

Old Dominion University, rmrobins@odu.edu

Follow this and additional works at: https://digitalcommons.odu.edu/vmasc_pubs

Part of the Civil Engineering Commons, Transportation Commons, and the Transportation Engineering Commons

\section{Repository Citation}

Duanmu, Jun; Foytik, Peter; Khattak, Asad; and Robinson, R. Michael, "Distribution Analysis of Freight Transportation with Gravity Model and Genetic Algorithm" (2012). VMASC Publications. 25.

https://digitalcommons.odu.edu/vmasc_pubs/25

\section{Original Publication Citation}

Duanmu, J., Foytik, P., Khattak, A., \& Robinson, R. M. (2012). Distribution analysis of freight transportation with gravity model and genetic algorithm. Transportation Research Record, 2269, 1-10. doi:10.3141/2269-01

This Article is brought to you for free and open access by the Virginia Modeling, Analysis \& Simulation Center at ODU Digital Commons. It has been accepted for inclusion in VMASC Publications by an authorized administrator of ODU Digital Commons. For more information, please contact digitalcommons@odu.edu. 


\title{
Distribution Analysis of Freight Transportation with Gravity Model and Genetic Algorithm
}

\author{
Jun Duanmu, Peter Foytik, Asad Khattak, and R. Michael Robinson
}

\begin{abstract}
The application of a gravity model in freight modeling work on both short-haul and long-haul trips is discussed. A commodity-based gravity model was developed to assess the distribution of freight by long-haul trucks in southeastern Virginia. Although gravity models have been used extensively in transportation studies, little work has been done to address the special characteristics of freight transportation, such as the definition of friction factors and the differences between long-haul and short-haul trips. Results of a recent study of these and similar problems provide valuable insight into freight distribution modeling. A new calibration method that used a genetic algorithm was applied, various commodities were modeled, and the impact of the commodities on the accuracy of the gravity model was studied. Both travel time and travel distance were tested to generate the impedance for friction factors; results showed that for commodity-based long-haul models, travel times were more appropriate for friction factor calculations. In addition, results showed that the gamma function was more suitable than the exponential function for friction factor calculations. Extensive analyses of the causes of variation between observed values and the gravity model outputs are provided. The analyses and conclusions may help modelers better understand characteristics specific to freight transportation and can promote model constructions with greater accuracy and efficiency.
\end{abstract}

This paper discusses the use of a gravity model with application of genetic algorithms (GAs) in freight modeling. A commodity-based gravity model was developed to assess the distribution of freight in southeastern Virginia, a region that contains 31 counties. Although considerable analysis using gravity models was done in previous transportation studies, little work specific to freight transportation, including the definition and use of friction factors, has been completed. The different characteristics of short-haul and long-haul freight trips generate different variations and affect the results in different ways. The cycle loops in short-haul local trips make the freight model hard to calibrate, and the economic factors generate special origin-destination (O-D) pairs that traditional gravity models cannot accurately replicate in long-haul freight trips. This paper studies such problems, and the results provide valuable insight into freight distribution modeling. The novel application of GA calibration was used

J. Duanmu, P. Foytik, and R. M. Robinson, Virginia Modeling, Analysis, and Simulation Center, Old Dominion University, 1030 University Boulevard, Suffolk, VA 23545. A. Khattak, Civil and Environmental Engineering Department, Old Dominion University, 135 Kaufman Hall, Norfolk, VA 23529. Corresponding author: J. Duanmu, jduanmu@odu.edu.

Transportation Research Record: Journal of the Transportation Research Board, No. 2269, Transportation Research Board of the National Academies, Washington, D.C., 2012, pp. 1-10.

DOI: 10.3141/2269-01 with various modeled commodities, and their impact on the accuracy of the gravity model was studied. Both travel time and travel distance were used to generate the impedance for friction factor; the results showed that for the commodity-based long-haul model, travel times were more appropriate for impedance modeling. Results suggest that the gamma function is more suitable than the exponential function for calculation of the friction factor. Extensive analysis of the causes of variation between observed and modeled values is provided. The analyses and conclusions may help modelers better understand characteristics specific to freight transportation and can promote model constructions with greater accuracy and efficiency.

\section{LITERATURE REVIEW}

Although a few standard techniques are repeatedly used to forecast the movement of passenger cars, similar consensus has not been achieved for modeling of freight transportation. In the past two decades, a series of documents and guidebooks have been published. NCHRP Report 606 systematically summarizes the newest techniques and solutions in freight modeling and provides examples of projects that apply these methodologies (1). NCHRP Report 606 defines five classes of freight models as follows:

1. Direct facility flow factoring,

2. O-D factoring method,

3. Truck model,

4. Four-step commodity model, and

5. Economic activity model.

These model classes share many basic components, including direct factoring, trip generation, trip distribution, modal split, traffic assignment, and economic and land use modeling. Not all components are included in each model class. NCHRP Report 606 discusses components and their application for individual model classes. However, freight modeling is complex. For example, there is no conclusive result or guidance showing how a gravity model can give an accurate replication of the behavior of freight distribution. Some real-world works provide less-than-ideal results with the use of gravity models. In the Hampton Roads travel demand forecasting model, truck trip distributions were tested with a gravity model, and the results are not sufficiently accurate (2).

Another key reference for freight modeling is the FHWA Quick Response Freight Manual II (QRFM) (3), which provides default values for estimating and forecasting trip generation in the general methodologies, such as the regression model and simple rates factors. Four basic methods are discussed: $(a)$ simple growth factor methods, (b) four-step travel forecasting, $(c)$ commodity-based forecast, and 
(d) economic models. The QRFM also suggests equations for friction factors used in the gravity model for various truck types.

The Guidebook on Statewide Travel Forecasting gives a general procedure for a statewide freight forecasting model (4). It focuses on the detailed methods that may be used in a four-step freight model. Along with general methodologies and principles, Demetsky et al. presented an example of a statewide freight demand forecast (5). A partition method that disaggregated integrated commodity production and attraction around the statewide region and a gravity model were used to generate O-D pairs. Several examples of statewide models represent special types of problems. Although most publications mention the use of a gravity model in freight trip distribution, few give a deep analysis of the reliability, accuracy, and limitations of such application. Without careful study of the characteristics of freight behavior, use of a gravity model could generate problematic outputs that do not accurately represent freight distribution.

\section{ANALYSIS OF SHORT-HAUL TRIPS}

\section{Trip Generation and Application Range: A Neglected and Unclear Issue}

Trip generation first estimates and then forecasts the productions and attractions of freight movements that begin or end in a transportation analysis zone. Trip generation models create daily or annual trips as functions of population or categorized employment data with derived trip rates from publicly recommended resources, such as the QRFM or regional resources. The various truck types generate different numbers of trips, and local trucks (short-haul) and long-distance trucks (long-haul) behave differently. Generally, long-haul trips are point-to-point trips, whereas short-haul trips often include multiple intermediate stops. Generated trips must be properly categorized according to their transportation behavior.

Long-haul transportation should be separated from short-haul trips. Long-haul trips usually proceed directly from the origin to the destination without intermediate stops. "Long-haul" refers to trips made directly between distribution centers (ports, warehouses, final destinations), not only to trips of longer distances. Fully loaded trucks travel long distances to maximize efficiency. Short-haul freight shippers pursue maximum routing efficiency for trips that may include numerous intermediate stops. Local customers often desire smaller quantities to reduce inventory costs, necessitating more frequent deliveries.

Figure 1 shows differences in destination types. Long-haul freight movements, such as those between counties, are predominately direct trips with full loads. Local trips often comprise loops. Traditional gravity models cannot properly replicate such mixed behavior modes and might generate O-D trips between these seven buildings that result in zero commodity exchange.

A stratified model process helps to minimize such mistakes. One level is constructed for long-haul trips. Another level is built for

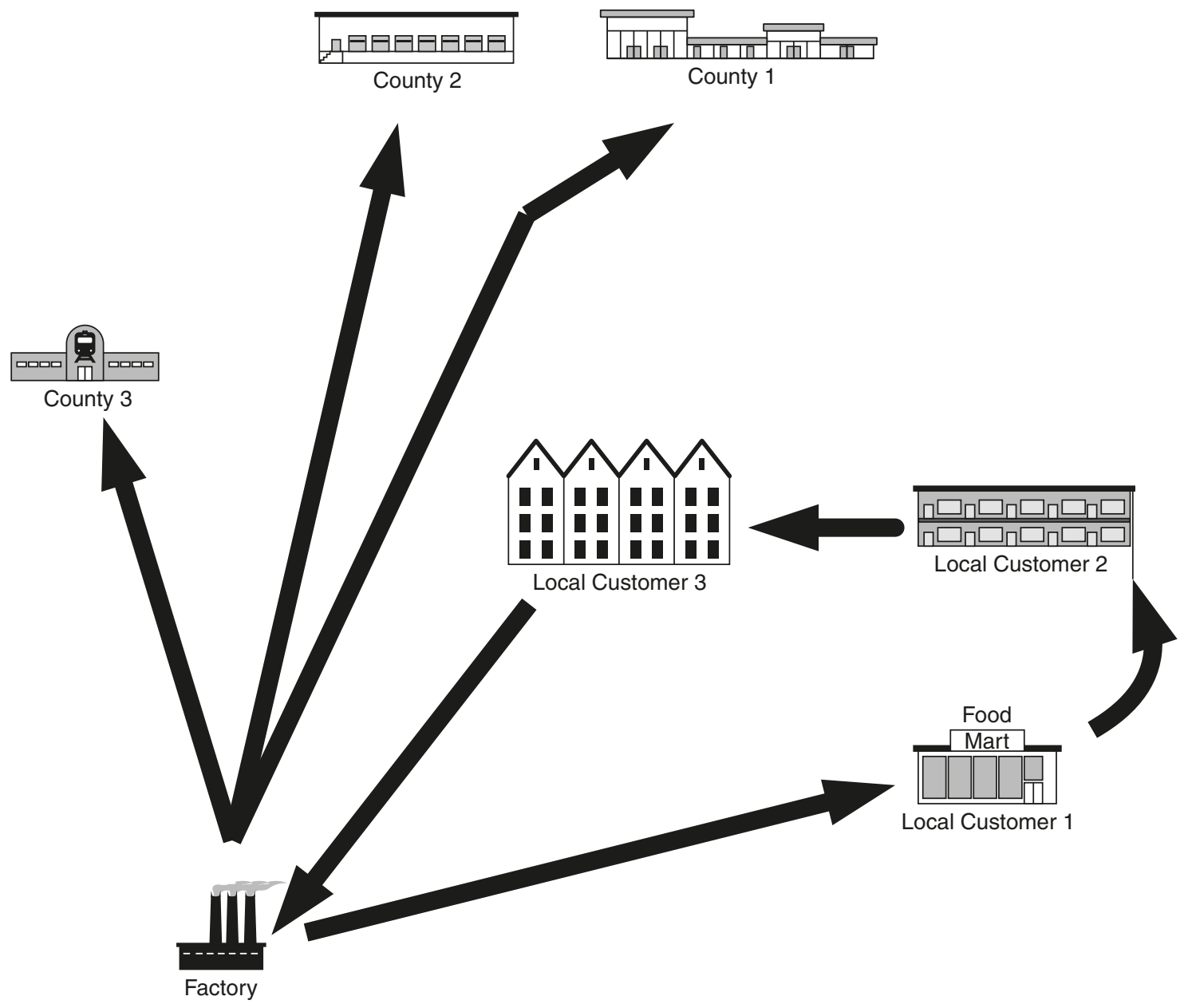

FIGURE 1 Long haul versus short haul. 
local transportation. Long-haul transportation involves study of freight flows along major corridors. Local truck trips can be ignored, and trips between county centroids are sufficiently accurate. Modeling accuracy is improved by correct placement of centroids and avoidance of trips within a transportation analysis zone. In countybased gravity models, centroids should be placed in the area that represents where most business units are located, not necessarily at the geographic center. Additionally, centroid locations must be close to a major highway that is included in the county-based model. When reliable location and commodity data are available with greater detail, accuracy can be improved by subdividing counties into smaller fine zones. However, commodity transfers must not be allowed to occur between fine zones within the same county, because those transfers could alter the true long-haul trips that are modeled.

\section{Local Short-Haul Trips and Traditional Gravity Method}

For local trucks, traditional trip generation algorithms and the gravity model can be used. However, there are special issues concerning truck trips.

First, the trip rate may not be accurate enough. For the same category of business unit, the daily trip total does not increase proportionally with the number of employees; often, the trip rate per employee decreases as the employee population increases (6).

Second, there are no trips between different types of businesses. For example, food stores will not attract trips generated from home improvement warehouses. The gravity model must be generated for different business categories. However, it is not easy to finely categorize these behaviors.

Finally, gravity models are based on macroeconomic theory and may not accurately mimic freight behaviors at the microscopic level. A simple example is shown in Figure 1. A looped route connects four zones: three customer zones and one factory zone. Each station has one production and one attraction in 1 day. With the intrazone and interzone travel times assumed to be equal (not in straight lines), as shown in Table 1, the gravity model will initially evenly distribute 0.25 trips to each O-D pair. In the real world, trips occur only between connected pairs in the loop. Some calibration

\begin{tabular}{|c|c|c|c|c|}
\hline \multirow{2}{*}{$\begin{array}{l}\text { Origin } \\
\text { Zone }\end{array}$} & \multicolumn{4}{|c|}{ Destination Zone } \\
\hline & 1 & 2 & 3 & 4 \\
\hline \multicolumn{5}{|c|}{ Gravity Model Application } \\
\hline 1 & 0.25 & 0.25 & 0.25 & 0.25 \\
\hline 2 & 0.25 & 0.25 & 0.25 & 0.25 \\
\hline 3 & 0.25 & 0.25 & 0.25 & 0.25 \\
\hline 4 & 0.25 & 0.25 & 0.25 & 0.25 \\
\hline \multicolumn{5}{|c|}{ Trip O-D Pairs in Reality } \\
\hline 1 & 0 & 1 & 0 & 0 \\
\hline 2 & 0 & 0 & 1 & 0 \\
\hline 3 & 0 & 0 & 0 & 1 \\
\hline 4 & 1 & 0 & 0 & 0 \\
\hline
\end{tabular}

work might adjust the value in this matrix; however, it is somewhat difficult to replicate the looped trips accurately with macroeconomic distribution theory, because gravity models always distribute trips from origin to any destination with nonzero attractions, but in the real world, special trip behaviors may keep some special O-D pairs with zero trips. Here this result is caused by looped route behavior. The later section on analysis of the high root mean square error (RMSE) addresses this problem in economic aspects for long-haul trips. A good trip modeling method is needed to provide adequate and accurate consideration of such trips. When short-haul trips do not use a looping route, traditional trip generation methods and the gravity model may still provide a reasonable approximation for local freight transport.

After appropriate categorization, either short- or long-haul trips can be modeled by the gravity model.

\section{GA AND CALIBRATION FOR LONG-HAUL COMMODITY-BASED GRAVITY MODEL}

\section{Data Preparation}

Before a gravity model is run, trips must be generated as production and attraction for each transportation analysis zone. NCHRP Synthesis 298 describes two types of truck trips: vehicle based and commodity based (7). Vehicle-based trip generation directly generates the number of truck trips. Commodity-based generation produces the flow of specific commodity types, which are converted into truck trips according to payload conversion factors. Commodity-based models are used for the large-area, county-level freight models associated with industrial or agriculture production or regional integrated demands. County-level freight flow models generated from direct economic activities can give a more accurate replication of the commodity flow behavior. Trip generation for local freight movements is more directly related to individual company size and daily business activities: models simulating local trucks may use regression models to generate the trip values for each business unit.

In this study, a commodity-based, county-level gravity model was constructed to cover 31 counties in southeastern Virginia, including Hampton Roads, the Richmond Tri-Cities area, and the intermediate counties connecting them. Detailed survey data of freight transportation between each county was obtained from the TRANSEARCH database (8). TRANSEARCH is an annually updated nationwide database of freight flows between U.S. county or zip code markets. The database uses four-digit standard transportation commodity codes to define the commodities. The database includes several hundred types of commodities with records for tonnage of each flowing between O-D pairs (county level) in the defined locations. To simplify the modeling effort, commodities were grouped into 10 basic categories. The productionattraction and O-D pairs for each category were obtained directly from the database. Table 2 gives the categorized commodities in the second column. Ten distribution matrixes with $31 \times 31 \mathrm{O}-\mathrm{D}$ pairs for each category were generated as the observed internal flow distribution value. Some of the commodities generate small productions and attractions and were not included in the gravity model. As shown in Table 2, Column 3, seven commodity types were selected. The travel time and travel distance between these 31 O-D pairs were also generated for the friction factor calculation. The RMSE and $T_{\mathrm{AV}}$ shown in Table 2, Columns 4 and 5, are discussed in later sections. 
TABLE 2 Categorized Commodities

\begin{tabular}{lllcc}
\hline $\begin{array}{l}\text { Category } \\
\text { Number }\end{array}$ & Description & $\begin{array}{l}\text { Selected for Gravity } \\
\text { Model Test }\end{array}$ & $\begin{array}{l}\text { RMSE from } \\
\text { Gamma Function }\end{array}$ & $\begin{array}{l}\text { Percentage } \\
\text { Difference of } T_{\mathrm{AV}}\end{array}$ \\
\hline 1 & Agriculture & Selected & 1.43 & 8.07 \\
2 & Foodstuffs & Selected & 1.1 & 2.03 \\
3 & Solid minerals fuels & Not selected & na & na \\
4 & Petroleum products & Not selected & na & na \\
5 & Ores and metal waste & Not selected & na & na \\
6 & Metal products & Selected & 4.18 & 8.48 \\
7 & Building materials & Selected & 1.74 & 8.05 \\
8 & Fertilizers & Selected & 1.9 & 2.76 \\
9 & Chemicals & Selected & 2.81 & 7.35 \\
10 & Manufactured goods & Selected & 1.8 & 6.80 \\
\hline
\end{tabular}

NoTE: $\mathrm{na}=$ not applicable.

\section{Gravity Model}

Unlike traditional gravity models for passenger trips, the gravity model for county-level freight flow predicts the directed flows between $\mathrm{O}-\mathrm{D}$ pairs by using commodity tonnage. Equation 1 shows the typical gravity model equation that is used for freight tonnage transportation:

$$
\begin{aligned}
T_{i j} & =P_{I} \frac{A_{j} F_{i j} K_{i j}}{\sum_{j} A_{j} F_{i j} K_{i j}} \\
F_{i j} & =\frac{1}{W_{i j}^{C}}
\end{aligned}
$$

where

$$
\begin{aligned}
T_{i j}= & \text { tonnage from zone } i \text { to } j ; \\
P_{I}= & \text { flow production in zone } i \\
A_{j}= & \text { flow attraction in zone } j ; \\
F_{i j}= & \text { friction factor relating to the spatial separation between } \\
& \text { zone } i \text { and zone } j ; \\
K_{i j}= & \text { optional zone-to-zone adjustment factor, called the } K \text {-factor } \\
& \text { or socioeconomic factor; and } \\
W_{i j}^{C}= & \text { impedance between zone } i \text { and } j \text { with a power of } C
\end{aligned}
$$

for any commodity category.

Considering the characteristics of freight transportation, two types of algorithms for friction factor $F_{i j}$ are used: $(a)$ the gamma function, in which the impedance is related only to travel time (with parameters $a, b$, and $c$ ), and (b) the exponential function, in which the impedance is formed by both travel time and travel distance.

Equation 3 is a gamma function from NCHRP Report 365, usually used in urban areas (9). In Equation 2, $F_{i j}$ is expressed as the power of the inverse of the interzonal impedance. If travel time $t_{i j}$ is used as the impedance criteria and $a=1$ and $c=0$, Equation 3 degenerates into Equation 2:

$F_{i j}=a t_{i j}^{b} e^{-c t_{i j}}$

where $t_{i j}$ is the travel time impedance.

The exponential function shown in Equation 4 is derived from Equation 3. The difference between the two equations is in the defini- tion of impedance. Equation 3 defines the impedance directly from travel time. Equation 4 uses multiple factors to define the impedance. The algorithm of impedance $G$ is described in Equation 5.

$\Phi(G)=e^{P G}$

where
$\Phi(G)$ = friction factor of generalized cost used in the gravity model, $G=$ generalized impedance, and $P=$ calibration parameter for a special commodity type.

$G(d, \tau, \chi)=k_{0}+k_{1} d+k_{2} \tau+k_{3} \chi$

where

$d=$ trip length in miles;

$\tau=$ journey time in minutes;

$\chi=$ direct monetary cost, which for road trips includes (fuel and nonfuel) vehicle operating costs and tolls;

$k_{0}=$ constant term;

$k_{1}=$ coefficient for distance;

$k_{2}=$ coefficient for travel time; and

$k_{3}=$ coefficient for monetary cost.

Generally, $\chi$ equals the mileage $d_{i j}$ multiplied by cost per mile $F_{C}$ as shown in Equation 6:

$\chi_{i j}=d_{i j} \times F_{C}$

If a series of initial values for $a, b, c, k, F_{C}$, and $P$ are set, the gravity model can generate an initial O-D matrix for all related zones. However, without calibration, those O-D matrixes are incorrect and cannot give an accurate forecast for freight distribution. The parameters and coefficients need to be calibrated first.

\section{Calibration of Gravity Model}

\section{Use of GAs in Model Calibration}

Gravity models can be calibrated with transportation software such as TRANPLAN or processed with iterative work. In this project, a 
GA was used to determine the best combination of parameters to minimize the errors between modeled output and observed values.

The RMSE is applied as the object value to determine the convergence status. The RMSEs between calculated $T_{i j}$ values and the observed values are assessed with the lower calculated RMSE representing a closer match of the calculated values to the observed. If the RMSE values remain stable after many iterations, the search process is stopped.

$$
\mathrm{RMSE}=\frac{\sqrt{\frac{\sum_{j=1}^{n} \sum_{i=1}^{n}\left(T_{i j}^{\mathrm{est}}-T_{i j}^{\mathrm{obs}}\right)^{2}}{n \times n}}}{\frac{\sum_{j=1}^{n} \sum_{i=1}^{n} T_{i j}^{\mathrm{obs}}}{n \times n}}
$$

where

$$
\begin{aligned}
T_{i j}^{\text {est }} & =\text { estimated tonnage from } i \text { to } j, \\
T_{i j}^{\text {obs }} & =\text { observed tonnage from } i \text { to } j, \text { and } \\
n & =\text { total number of zones. }
\end{aligned}
$$

A GA is a technique inspired by processes that utilize natural evolution, such as inheritance, mutation, selection, and crossover. Evolution is described as the natural process of survival of the fittest for a population. In the GA context, evolution is the process of survival of the fittest genome of a population, or the parameter set that produces the best results within a population. Genomes are made up of a value or set of values that allows the algorithm to change to find the best genome. Genomes are usually coded as a series of strings, simulating chromosomes, a nod to the medical origins of the process. In this project, the GA uses a series of parameters for the friction factor equation as a genome and applies them to calculation of the gravity model. The optimization process is carried out through natural selection as each generation progresses. Parent genomes can use any or all of the following: reproduction to create new children or genomes, a crossover method to mix their chromosomes, or mutation to completely alter their chromosomes. A stochastic selection process selects children of the best fitness (also known as genomes) and uses them as the parents of the next generation.

Figure 2 shows the order and process of the GA in conjunction with the gravity model. The GA starts with the genome produce function by initially creating random genomes within typical ranges of the gravity model parameters. The gravity model runs a set of genomes producing a freight tonnage distribution that the population read function inputs, then adds the new genomes to the existing population of previously run genomes. The GA compares the read tonnage distribution to the measured tonnage distribution to calculate RMSE values for each genome. A population rank function then takes the current population of genomes and ranks them in order of best RMSE values. The 10 best RMSE valued genomes remain and are used as parents for the next generation; other genomes are discarded. At this point, the algorithm compares the newly formed population of genomes and the previous population to measure the difference based on a convergence measure outlined in the next section. If convergence is met or the maximum number of iterations has run, then the algorithm stops and the top 10 genomes are reported. This study set the maximum number of iterations to 500. If convergence is not met after 500 iterations, the algorithm proceeds to the next step, a mate and mutate function. The mate function consists of the reproduction of a new genome from two randomly selected

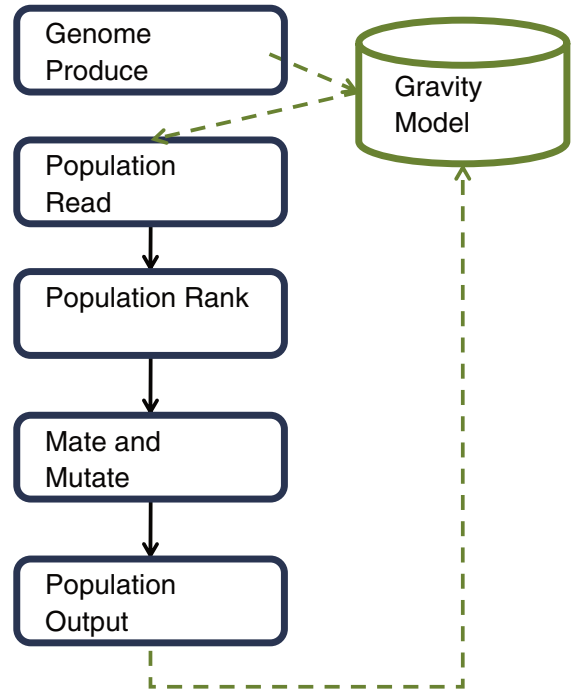

FIGURE 2 Major components of GA design.

genomes existing in the current population. The new genome is created with each of its parameters being a random value bracketed by parameters of the parent's genomes. Along with reproduction, a random set of children within the population is assessed to have the opportunity to mutate, which is accomplished by randomly selecting parameters within the selected genome and randomizing the value within the initial ranges. Mutations are used to attempt to avoid getting stuck within a local minimum of the problem space. GAs have been used in many transportation studies; Foytik and Cetin used a GA to find an accurate volume-delay function for Hampton Roads and Charlottesville (10). Other studies that used GAs are that of Kalic and Teodorovic (11), where GAs were used to determine passenger car distribution, and that of Qiu (12), which used GAs to calibrate gravity and logit models.

\section{Evaluation of Modeling Results: Convergence}

It is expected that for a good convergence, the average trip length $T_{\mathrm{AV}}$ will have a difference of less than $10 \%$ compared with the observed value:

$T_{\mathrm{AV}}=\sum_{i=1}^{k} P_{i} \times D_{i}$

where $k$ is the total number of distance interval sets in the model and $P_{i}$ is the transportation tonnage percentage of the $i$ th distance interval $D_{i}$.

\section{K-Factor Adjustment}

After numerous GA iterations, the value of RMSE could still be large. $K$-factors may be applied to partially adjust for some zones if socioeconomic conditions cause abnormal skews from regular distribution.

$K_{i j}=R_{i j} \frac{1-X_{i j}}{1-X_{i j} R_{i j}}$ 
where $R_{i j}$ is the ratio of observed tonnages to the calculated flows from zone $i$ to zone $j$ and $X_{i j}$ is the ration of O-D flows to the total O-D flows leaving zone $i$.

Equation 9 is applied if $10 \%$ to $40 \%$ of the flow is leaving a zone. For other conditions, $R_{i j}$ should be used as the $K$-factor. In general, use of $K$-factors is not recommended (13).

\section{Constraint and Search Range for Design Variables}

In a GA, a predefined search range for each design variable is set according to historical values and guidance (9):

1. Values for exponential function for friction factors:

- Travel cost $F_{C}: 1<F_{C}<2.5$,

$-k_{1}=0$,

$-k_{2}=-1$ to -0.01 ,

$-k_{3}=-1$ to -0.01 , and

$-P=0.01$ to 10 and

2. Values for gamma function for friction factors:

$-a=20,000$ to 300,000 (integer),

$-b=-1$ to 1 , and

$-c=0.01$ to 1 .

\section{Result Analysis and Discussion}

After extensive GA searches, optimized values of parameters are input to the gravity model. The model output provides some consistent results: the RMSE value is high with all values greater than 1 (Table 2, Column 4), and the relative difference of average of trip length $T_{\mathrm{AV}}$ is relatively low; all are less than $10 \%$.

Another way to analyze $T_{\mathrm{AV}}$ is to check the tonnage distribution along the defined distance intervals. The distributed tonnage obtained from the calibrated model can be compared with the value from TRANSEARCH. The tonnage distribution shown in Figure 3 demonstrates a well-matched result; even the worst RMSE value (in Commodity Category 6) shows a relatively good match. However, the RMSE values present a high level of variance in individual O-D pairs. The friction factor used in Figure 3 was generated from the gamma function in Equation 3. Friction factors defined as the function of both travel costs and travel time in Equation 5 yield higher RMSE values. These results are not included in the table. In this case, the gamma function is more suitable for calculation of the friction factor.

During the search process with the GA, socioeconomic factors $(K$-factors) were not used $(=1)$. The following are possible reasons for the high RMSE:

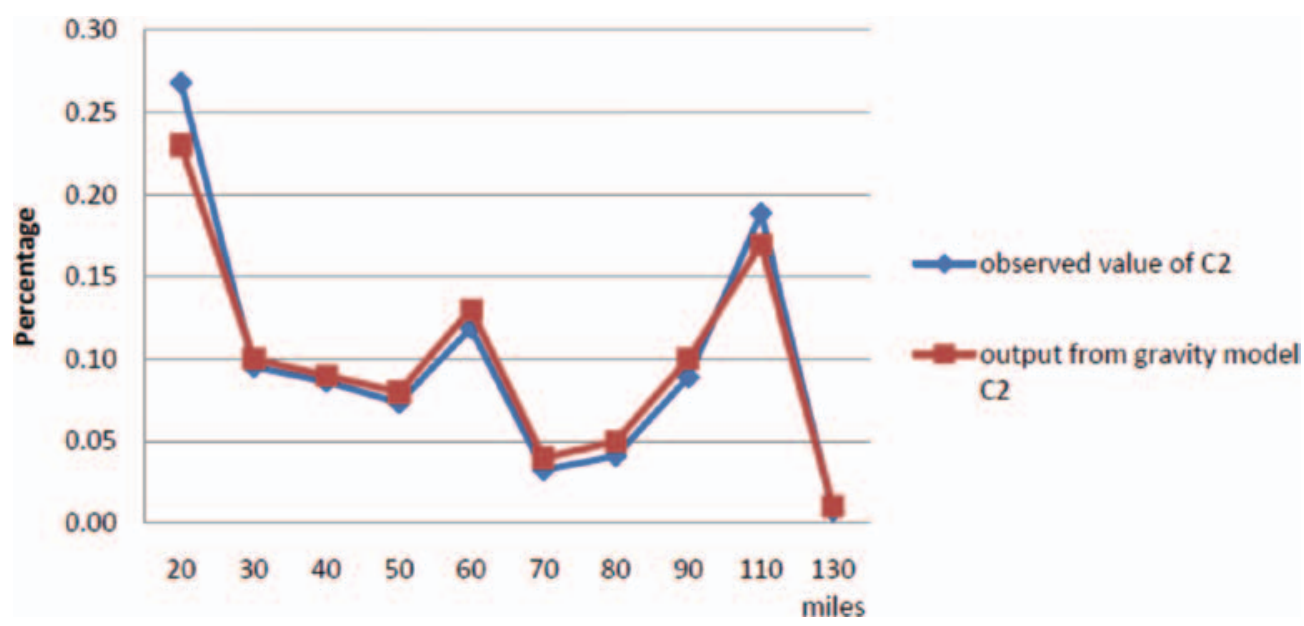

(a)

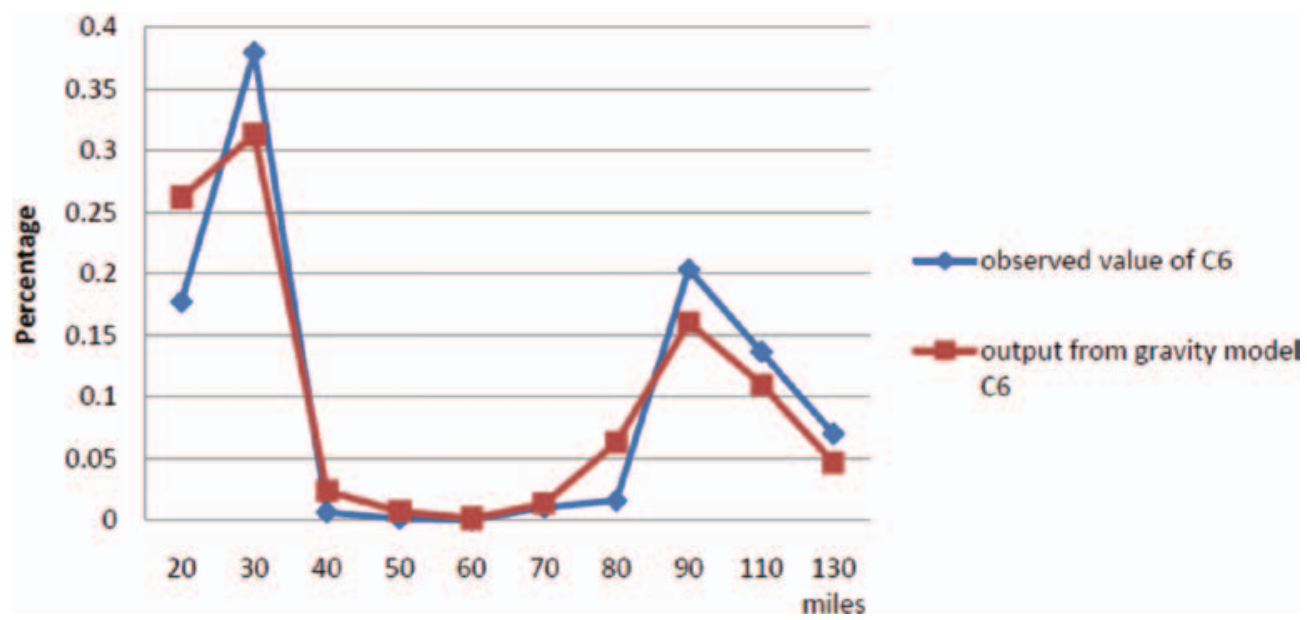

(b)

FIGURE 3 Tonnage distribution: (a) food (Category 2 ) and (b) metals (Category 6). 
1. The search range is not wide enough for location of the optimal points.

2. Some economic behaviors give freight transportation its own special characteristics.

3. The relatively low value of truck flow makes the variation more obvious and thus enlarges the RMSE value.

4. The gravity model without $K$-factors might be insufficient to represent freight flow behaviors.

\section{Analysis of High RMSE}

It is not a unique case that RMSE values after calibration are higher than 1. Mao and Demetsky noted the issue when they calibrated the freight flow gravity model for county-level freight transportation in Virginia (13). Characteristics related only to freight transportation should be carefully studied: commodity-related factors, intrazone variance, and statistical analysis.

\section{Commodity-Related Factors}

Some commodities have a high RMSE in gravity model calibration, whereas others generate relatively better results. In Table 2, metal products (Category 6) show the highest variance. Category 6 includes primary metal products, such as electrometallurgical products, steel wire, and aluminum or alloy castings. These products have only a few providers and consumers, which produces specific business partners as O-D pairs. The freight flow between such business pairs cannot simply be modeled with gravity models. Table 3 demonstrates such errors. The distributions (rounded to integer) of O-D pairs from the first 14 counties are shown in the tables. The observed values in Table 3 are from the TRANSEARCH database. In Origin Zone 10, the commodities produced are transported to Zone 2 only. In the gravity model, because other zones also have attractions, the commodities produced from Zone 10 are distributed to any zones that have nonzero attraction. The quantity of distributed goods is decided by the distance and attractiveness of the

TABLE 3 Comparison of Model Output for O-D Pairs

\begin{tabular}{|c|c|c|c|c|c|c|c|c|c|c|c|c|c|c|}
\hline \multirow{2}{*}{$\begin{array}{l}\text { Origin } \\
\text { Zone }\end{array}$} & \multicolumn{14}{|c|}{ Destination Zone } \\
\hline & 1 & 2 & 3 & 4 & 5 & 6 & 7 & 8 & 9 & 10 & 11 & 12 & 13 & 14 \\
\hline \multicolumn{15}{|c|}{ Observed Value } \\
\hline 1 & 0 & 0 & 0 & 0 & 0 & 0 & 0 & 0 & 0 & 0 & 0 & 0 & 0 & 0 \\
\hline 2 & 0 & 0 & 30 & 0 & 0 & 1,603 & 1,921 & 27 & 0 & 170 & 0 & 0 & 2,148 & 99 \\
\hline 3 & 0 & 0 & 0 & 0 & 0 & 0 & 0 & 0 & 0 & 0 & 0 & 0 & 0 & 0 \\
\hline 4 & 0 & 0 & 0 & 0 & 0 & 0 & 0 & 0 & 0 & 0 & 0 & 0 & 0 & 0 \\
\hline 5 & 0 & 0 & 0 & 0 & 0 & 0 & 0 & 0 & 0 & 0 & 0 & 0 & 0 & 0 \\
\hline 6 & 0 & 46 & 0 & 0 & 0 & 0 & 0 & 0 & 0 & 0 & 0 & 0 & 42 & 0 \\
\hline 7 & 0 & 23,209 & 37 & 0 & 0 & 2,225 & 45 & 35 & 0 & 172 & 0 & 0 & 2,844 & 153 \\
\hline 8 & 0 & 0 & 0 & 0 & 0 & 0 & 0 & 0 & 0 & 0 & 0 & 0 & 0 & 0 \\
\hline 9 & 0 & 0 & 0 & 0 & 0 & 0 & 0 & 0 & 0 & 0 & 0 & 0 & 0 & 0 \\
\hline 10 & 0 & 136,793 & 0 & 0 & 0 & 0 & 0 & 0 & 0 & 0 & 0 & 0 & 0 & 0 \\
\hline 11 & 0 & 0 & 0 & 0 & 0 & 0 & 0 & 0 & 0 & 0 & 0 & 0 & 0 & 0 \\
\hline 12 & 0 & 0 & 0 & 0 & 0 & 0 & 0 & 0 & 0 & 0 & 0 & 0 & 0 & 0 \\
\hline 13 & 0 & 6,508 & 5 & 0 & 0 & 428 & 456 & 0 & 0 & 25 & 0 & 0 & 0 & 16 \\
\hline 14 & 0 & 1,691 & 0 & 0 & 0 & 42 & 32 & 0 & 0 & 0 & 0 & 0 & 61 & 0 \\
\hline \multicolumn{15}{|c|}{ Gravity Model Value } \\
\hline 1 & 0 & 0 & 0 & 0 & 0 & 0 & 0 & 0 & 0 & 0 & 0 & 0 & 0 & 0 \\
\hline 2 & 0 & 22,078 & 13 & 2 & 0 & 982 & 554 & 13 & 0 & 75 & 0 & 0 & 862 & 52 \\
\hline 3 & 0 & 0 & 0 & 0 & 0 & 0 & 0 & 0 & 0 & 0 & 0 & 0 & 0 & 0 \\
\hline 4 & 0 & 0 & 0 & 0 & 0 & 0 & 0 & 0 & 0 & 0 & 0 & 0 & 0 & 0 \\
\hline 5 & 0 & 0 & 0 & 0 & 0 & 0 & 0 & 0 & 0 & 0 & 0 & 0 & 0 & 0 \\
\hline 6 & 0 & 111 & 0 & 0 & 0 & 1 & 1 & 0 & 0 & 0 & 0 & 0 & 3 & 0 \\
\hline 7 & 0 & 37,073 & 11 & 2 & 0 & 779 & 252 & 11 & 0 & 67 & 0 & 0 & 793 & 45 \\
\hline 8 & 0 & 0 & 0 & 0 & 0 & 0 & 0 & 0 & 0 & 0 & 0 & 0 & 0 & 0 \\
\hline 9 & 0 & 0 & 0 & 0 & 0 & 0 & 0 & 0 & 0 & 0 & 0 & 0 & 0 & 0 \\
\hline 10 & 0 & 108,769 & 8 & 6 & 0 & 2,281 & 1,427 & 20 & 0 & 26 & 0 & 0 & 2,557 & 157 \\
\hline 11 & 0 & 0 & 0 & 0 & 0 & 0 & 0 & 0 & 0 & 0 & 0 & 0 & 0 & 0 \\
\hline 12 & 0 & 0 & 0 & 0 & 0 & 0 & 0 & 0 & 0 & 0 & 0 & 0 & 0 & 0 \\
\hline 13 & 0 & 9,449 & 3 & 1 & 0 & 249 & 130 & 3 & 0 & 20 & 0 & 0 & 139 & 15 \\
\hline 14 & 0 & 1,784 & 1 & 0 & 0 & 34 & 23 & 1 & 0 & 4 & 0 & 0 & 46 & 2 \\
\hline
\end{tabular}

NoTE: $P_{i}$ for origin zones: $1=0 ; 2=34,393 ; 3=0 ; 4=0 ; 5=0 ; 6=141 ; 7=48,336 ; 8=0 ; 9=0 ; 10=136,793 ; 11=0 ; 12=0 ; 13=12,964$; $14=2,308 . A_{j}$ for destination zones: $1=0 ; 2=272,758 ; 3=72 ; 4=15 ; 5=0 ; 6=5,747 ; 7=3,570 ; 8=72 ; 9=0 ; 10=424 ; 11=0 ; 12=0$; $13=6,566 ; 14=401$. 
destination. Therefore, the tonnage distribution is still in a relatively accurate range while contributing many distribution errors. These errors come from two sources of variance: $(a)$ the amount of goods removed from original destination zones and $(b)$ the amount of goods transferred to attraction zones that should not have attractions. Consequently, this type of distribution of commodities can generate high RMSE. Therefore, a rarely used commodity may cause high variance in the gravity model.

For more general commodities, such as foodstuff (Category 2) and manufactured goods (Category 10), the RMSE values are much lower. However, the special supplier-consumer relationship still can generate considerable errors.

Table 4 shows the gravity model output for foodstuff (rounded to integer) and the observed values of O-D pairs for the first 14 zones. All zones except Zone 1 attract foodstuff, but production zones do not deliver foodstuff to every attraction place. Zone 3, for example, delivers only to Zones 7 and 13. Consequently, many O-D pairs that should generate no freight flow become nonzero in the output and therefore generate high variance.

\section{Intrazone Variance}

The gravity model may generate nonzero intrazonal freight, but flows within a zone are unpredictable. In Table 3, Zone 2 attracted a large amount of production, but none is internal transportation. However, the gravity model allocated a considerable amount of local production to Zone 2, causing high variance. Table 4 is similar; in Zones 2, 7, and 10 , the intrazone attraction value generated high variance.

\section{Statistical Analysis}

The gravity model illustrates the macroscopic travel distribution relationships between traffic zones. Although it successfully explains

TABLE 4 Comparison of Model Output for Foodstuff

\begin{tabular}{|c|c|c|c|c|c|c|c|c|c|c|c|c|c|c|}
\hline \multirow{2}{*}{$\begin{array}{l}\text { Origin } \\
\text { Zone }\end{array}$} & \multicolumn{14}{|c|}{ Destination Zone } \\
\hline & 1 & 2 & 3 & 4 & 5 & 6 & 7 & 8 & 9 & 10 & 11 & 12 & 13 & 14 \\
\hline \multicolumn{15}{|c|}{ Observed Value } \\
\hline 1 & 0 & 0 & 0 & 0 & 0 & 0 & 0 & 0 & 0 & 0 & 0 & 0 & 0 & 0 \\
\hline 2 & 0 & 200 & 151 & 705 & 132 & 772 & 6,892 & 222 & 0 & 507 & 732 & 256 & 3,389 & 0 \\
\hline 3 & 0 & 0 & 0 & 0 & 0 & 0 & 193 & 0 & 0 & 0 & 0 & 0 & 11 & 0 \\
\hline 4 & 0 & 1,573 & 0 & 20,789 & 0 & 0 & 3,673 & 0 & 0 & 0 & 0 & 0 & 175 & 0 \\
\hline 5 & 0 & 0 & 0 & 0 & 0 & 0 & 0 & 0 & 0 & 0 & 0 & 0 & 0 & 0 \\
\hline 6 & 0 & 0 & 0 & 0 & 0 & 0 & 651 & 1,670 & 0 & 0 & 0 & 0 & 0 & 0 \\
\hline 7 & 0 & 41,873 & 625 & 1,859 & 387 & 3,842 & 567 & 1,215 & 196 & 1,964 & 377 & 908 & 22,356 & 188 \\
\hline 8 & 0 & 0 & 0 & 0 & 0 & 0 & 0 & 0 & 0 & 0 & 0 & 0 & 0 & 0 \\
\hline 9 & 0 & 0 & 0 & 0 & 0 & 0 & 0 & 0 & 0 & 0 & 0 & 0 & 0 & 0 \\
\hline 10 & 0 & 1,702 & 0 & 0 & 0 & 0 & 324 & 0 & 0 & 0 & 0 & 0 & 19 & 0 \\
\hline 11 & 0 & 0 & 0 & 0 & 0 & 0 & 0 & 0 & 0 & 0 & 0 & 0 & 0 & 0 \\
\hline 12 & 0 & 0 & 0 & 0 & 0 & 0 & 0 & 0 & 0 & 0 & 0 & 0 & 0 & 0 \\
\hline 13 & 0 & 15,152 & 93 & 505 & 44 & 1,176 & 11,025 & 252 & 0 & 663 & 66 & 257 & 0 & 0 \\
\hline 14 & 0 & 0 & 0 & 0 & 0 & 0 & 476 & 0 & 0 & 0 & 0 & 0 & 0 & 0 \\
\hline \multicolumn{15}{|c|}{ Gravity Model Value } \\
\hline 1 & 0 & 0 & 0 & 0 & 0 & 0 & 0 & 0 & 0 & 0 & 0 & 0 & 0 & 0 \\
\hline 2 & 0 & 2,742 & 97 & 1,200 & 43 & 772 & 4,685 & 340 & 14 & 442 & 58 & 224 & 2,925 & 14 \\
\hline 3 & 0 & 100 & 0 & 21 & 1 & 14 & 93 & 4 & 0 & 2 & 1 & 3 & 65 & 0 \\
\hline 4 & 0 & 4,479 & 78 & 479 & 30 & 581 & 4,093 & 275 & 10 & 350 & 51 & 180 & 3,146 & 13 \\
\hline 5 & 0 & 0 & 0 & 0 & 0 & 0 & 0 & 0 & 0 & 0 & 0 & 0 & 0 & 0 \\
\hline 6 & 0 & 462 & 8 & 94 & 3 & 24 & 382 & 28 & 1 & 37 & 6 & 18 & 295 & 1 \\
\hline 7 & 0 & 27,822 & 541 & 6,609 & 172 & 3,807 & 13,832 & 1,886 & 75 & 2,459 & 403 & 1,240 & 16,823 & 76 \\
\hline 8 & 0 & 0 & 0 & 0 & 0 & 0 & 0 & 0 & 0 & 0 & 0 & 0 & 0 & 0 \\
\hline 9 & 0 & 0 & 0 & 0 & 0 & 0 & 0 & 0 & 0 & 0 & 0 & 0 & 0 & 0 \\
\hline 10 & 0 & 504 & 3 & 106 & 4 & 70 & 469 & 20 & 1 & 7 & 6 & 12 & 331 & 1 \\
\hline 11 & 0 & 0 & 0 & 0 & 0 & 0 & 0 & 0 & 0 & 0 & 0 & 0 & 0 & 0 \\
\hline 12 & 0 & 0 & 0 & 0 & 0 & 0 & 0 & 0 & 0 & 0 & 0 & 0 & 0 & 0 \\
\hline 13 & 0 & 7,690 & 169 & 2,268 & 74 & 1,314 & 7,474 & 608 & 24 & 775 & 127 & 408 & 3,309 & 27 \\
\hline 14 & 0 & 133 & 3 & 34 & 1 & 17 & 121 & 9 & 0 & 12 & 2 & 6 & 95 & 0 \\
\hline
\end{tabular}

NoTE: $P_{i}$ for origin zones: $1=0 ; 2=31,910 ; 3=646 ; 4=26,370 ; 5=0 ; 6=2,898 ; 7=182,635 ; 8=0 ; 9=0 ; 10=3,236 ; 11=0 ; 12=0 ; 13=60,712 ; 14=954$. $A_{j}$ for destination zones: $1=0 ; 2=127,791 ; 3=2,123 ; 4=27,581 ; 5=934 ; 6=17,528 ; 7=118,106 ; 8=7,249 ; 9=303 ; 10=9,564 ; 11=1,576 ; 12=4,769 ; 13=86,831 ; 14=357$. 
the choice of a large number of passenger trips, the choice of any given individual can vary from the aggregately predicted value. The variances generated in freight trips can affect the RMSE in a more obvious way.

Equation 7 is the RMSE calculation method applied in calibration of the gravity model. For each observed value of the O-D pairs, the magnitude of tonnage or trips can be regarded as the average value of a sample group. The gravity model output can be used as the theoretical value of the possible O-D flows. As an example of the gravity model, for general trips the RMSE may be around $30 \%$ of the theoretic value, and on average, the standard deviation of the observed value is $30 \%$ of the nominal value. Thus, the RMSE of truck trips can be estimated as follows. For a randomly selected O-D pair, it is assumed that the value of trips is $m$ and the variance of trip value that may not be distributed on that O-D pair is $\sigma^{2}$ for each of $m$ vehicle trips. In total, the range of the estimated trips $T$ with one standard deviation between this O-D pair can be expressed as $T=m \pm \sqrt{m} \times \sigma$. Thus the ratio $R_{1}$ between average trip and standard deviation is

$R_{1}=\frac{\sqrt{m} \times \sigma}{m}$

In Virginia, the primary truck type for long-haul freight is the onetrailer truck. One-trailer trucks on most of the major county-level roads represent approximately $10 \%$ of the flow, per the observed value of annual average daily traffic. For $10 \%$ of the total flow in that O-D, the trip range becomes $T_{10 \%}=10 \% \times m \pm \sqrt{10 \% \times m \times \sigma^{2}}$.

This time the ratio $R_{2}$ between average trip and standard deviation is

$R_{2}=\frac{\sqrt{10 \% \times m} \times \sigma}{10 \% \times m}=\sqrt{10} R_{1}$

The relative range of error increases more than three times if only $10 \%$ of the trips are interchanged between an O-D pair. Statistically, the bigger the sample group size, the less the relative error affects the nominal value. Thus, gravity models of passenger trips generate fewer RMSEs than freight models. By a rough estimation, according to the RMSE calculation method in Equation 7, if the RMSE in a general passenger model is $30 \%$, the correspondent value for a freight model may be higher than 1 . Here, it is assumed that the calibrated gravity model can output an unbiased estimation of trip interchanges between that O-D pair.

\section{K-Factors and Socioeconomic Considerations}

In a county-based freight model, the $K$-factor in Equation 1 can be used for calibration. Although the $K$-factor mechanism is still unclear (13), its contribution to convergence is clear. During a test, while $K$-factors were added after the GA search, the RMSE decreased quickly to a small value. The $K$-factor considers the socioeconomic situation for each O-D pair in the matrix, and it adjusts the freight flow toward the observed values. The effect is equal to a simulated special business relationship between this O-D pair.

Some statewide freight transportation models, including New Jersey's statewide model truck trip table update project and the Southern California Association of Governments heavy-duty truck model ( 1 ), used $K$-factors in calibration work. $K$-factors can be used to forecast the freight flow on the upgraded network. For short-term and medium-term forecasts, the $K$-factor could be useful and give a reliable forecast. However, inaccurate results could be generated if $K$-factors are used in long-term forecasts because the socioeconomic situation might change in the long term. In that case, the O-D factoring or the direct facility flow factoring method may give a more accurate forecast in a socioeconomic analysis (1).

It can be assumed that if the freight trips for various commodities are integrated, because of the increase in number of trips the RMSE might decrease. However, gravity models cannot relate the additional trips to real business activities. For example, if one type of commodity increases significantly, additional freight flow will be distributed to special related receivers; however, in the integrated gravity model, those total trips are redistributed to any possible receivers and thus bring extra variance. This redistribution may cause even more variance in forecasting.

\section{CONCLUSION}

This paper analyzed the gravity model for freight distribution on both short-haul and long-haul trips. The research indicates that uncategorized trips and looped routes in short-haul trips can make the traditional gravity model difficult to calibrate. To study long-haul trips, a commodity-based countywide freight distribution model was constructed and calibrated with GA. The results show that a gamma function that uses travel time as the deterrence factor generates better approximations for the gravity model than an exponential expression using both time and travel costs as deterrence factors. The commoditybased model shows relatively large RMSE values, and the major sources of deviation originate from characteristics specific to freight transportation:

1. Freight transportation behavior is sensitive to the interchanged commodities. Some suppliers may have unique relationships with certain consumers, which the gravity model may not be able to accurately capture in the O-D interchange volumes.

2. The intrazone freight distribution generated by the gravity model is greater than the observed data (the model is origin constrained). Hence, the difference generates additional deviations for the gravity model.

3. There is much less truck traffic than passenger vehicle trips; therefore, the relative errors compared with the gravity model output are higher. It may be difficult to obtain a gravity model with parameters that can generate a small RMSE.

This research applies a new solution for commodity-based gravity model calibration in freight transportation modeling. GAs can generate relatively accurate parameters for friction factors. Because commodities must be divided into multiple categories and calibration work must be accomplished on each of the corresponding gravity models, the workload can be heavy. Compared with the traditional iterative method, a GA search is efficient for calibration of gravity models and saves time. In addition, because there are no iterative and regression parameters in the estimation process, errors and deviations generated in related approximation work can be avoided. With more generalized commodity categories, such as food, the gravity model can give more accurate approximations of freight distribution.

The solution and discussions in this study clearly show the mechanisms within freight transportation behavior, helping freight modelers make efficient decisions about methodologies and solution approaches. New ranges for control variables have been set up to 
allow the GA model to start a wider search. Gravity models are efficient for passenger trip distribution; however, because of the limited number of trips and commodity-related transportation characteristics, additional analysis of business behavior and calibration work are necessary for generation of an accurate and reliable gravity model for freight distribution forecasts.

\section{ACKNOWLEDGMENT}

This study was supported by the U.S. Department of Transportation.

\section{REFERENCES}

1. Cohen, H., A. Horowitz, and R. Pendyala. NCHRP Report 606: Forecasting Statewide Freight Toolkit. Transportation Research Board of the National Academies, Washington, D.C., 2008.

2. Hampton Roads Travel Demand Forecasting Model, Truck Model Technical Report. Virginia Department of Transportation, Richmond, 2009.

3. Quick Response Freight Manual II. FHWA, U.S. Department of Transportation, 2007.

4. Guidebook on Statewide Travel Forecasting. FHWA, U.S. Department of Transportation, 1999.

5. Demetsky, M.J., C.J. Eatough, and S.C. Brich. A Methodology for Statewide Intermodal Freight Transportation Planning. Virginia Transportation Research Council, Charlottesville, 1998.
6. Holguín-Veras, J., M. Jaller, L. Destro, X. Ban, C. Lawson, and H. S. Levinson. Freight Generation, Freight Trip Generation, and Perils of Using Constant Trip Rates. In Transportation Research Record: Journal of the Transportation Research Board, No. 2224, Transportation Research Board of the National Academies, Washington, D.C., 2011, pp. 68-81.

7. NCHRP Synthesis of Highway Practice 298: Truck Trip Generation Data. TRB, National Research Council, Washington, D.C., 2001.

8. Global Insight. North American Commerce and Transport Data. http:// www.ihsglobalinsight.com/ProductsServices/ProductDetail1024.htm. Accessed June 19, 2011.

9. Martin, W. A., and N. A. McGuckin. NCHRP Report 365: Travel Estimation Techniques for Urban Planning. TRB, National Research Council, Washington, D.C., 1998.

10. Foytik, P., and M. Cetin. Using Genetic Algorithms to Estimate the Parameters of Volume Delay Functions. Presented at 90th Annual Meeting of the Transportation Research Board, Washington, D.C., 2011.

11. Kalic, M., and D.A. Teodorovic. Trip Distribution Modeling Using Fuzzy Logic and a Genetic Algorithm. Transportation Planning and Technology, Vol. 26, No. 3, 2003, pp. 213-238.

12. Qiu, M. Simultaneous Calibration of Gravity and Logit Models of Road Traffic by a Genetic Algorithm. Proc., IEEE International Conference on Evolutionary Computation, Perth, Western Australia, Australia, IEEE, Piscataway, N.J., 1995.

13. Mao, S., and M. J. Demetsky. Calibration of the Gravity Model for Truck Freight Flow Distribution. Center for Transportation Studies, University of Virginia, Charlottesville, 2002.

The Freight Transportation Planning and Logistics Committee peer-reviewed this paper. 